\title{
Role of laparoscopy in infertility in a rural setup hospital
}

\section{Sawaranalata Samal, Sweta Agrawal*, Madhuprita Agrawal}

Department of Obstetrics \& Gynaecology, Acharya Vinoba Bhave Rural Hospital, Wardha, Maharashtra, India

Received: 6 February 2014

Accepted: 16 February 2014

\section{*Correspondence:}

Dr. Sweta Agrawal,

E-mail: msa.sweta@gmail.com

(C) 2014 Samal S et al. This is an open-access article distributed under the terms of the Creative Commons Attribution Non-Commercial License, which permits unrestricted non-commercial use, distribution, and reproduction in any medium, provided the original work is properly cited.

\section{ABSTRACT}

Background: Infertility is a major health issue with multifactorial etiology. None of the laboratory findings alone is conclusive in diagnosing infertility. A minimally invasive method such as laparoscopy has come into play in finding the etiology and planning the further management of infertility. This study is intended to focus the role of laparoscopy in finding the causes of infertility in a rural set up area.

Methods: 100 cases of primary and secondary infertility were subjected to laparoscopy after taking informed consent. Causes of infertility were found out. The present study was conducted at Acharya Vinoba Bhave Rural Hospital, Wardha from 2011-2013.

Results: There were 75 cases $(75 \%)$ of primary infertility as against 25 cases (25\%) of secondary infertility. A maximum of 40 cases $(40 \%)$ were in the age group of 20 - 25 years. Uterine causes contributed about 14 cases (14\%), tubal causes contributed about $34(34 \%)$, ovarian factors accounted for 27 cases $(27 \%)$, peritoneal causes contributed for 7 cases (7\%), unexplained infertility accounted for 18 cases $(18 \%)$.

Conclusions: Laparoscopy is a gold standard for tubal, ovarian cases, in cases of endometriosis and in adhesions till date. Laparoscopy can be used for evaluation of almost all the cases of infertility. Because of its potential diagnostic and therapeutic benefits, all the patients with infertility should undergo laparoscopy prior to any advance procedure in infertility management. Diagnostic laparoscopy has become so important in the evaluation of infertility that it has now been considered as a basic skill which should be learnt by every gynaecologist in the advanced scientific era.

Keywords: Infertility, Primary infertility, Secondary infertility, Laparoscopy

\section{INTRODUCTION}

Infertility is a couple oriented diseases; still today 12$14 \%^{1}$ of couple are infertile. WHO estimates that 60 to 80 million couples worldwide currently suffer from infertility. ${ }^{2}$ Incidence of female infertility is $45.67 \%$, male infertility is $54.33 \%^{3}$ \& may be both can get involved in some of cases, range varies from region to region.

Total infertility is divided into primary and secondary infertility. Definitions of primary infertility vary between studies, but the operational definition, put forth by the WHO, defines primary infertility as "Inability to conceive within two years of exposure to pregnancy (i.e. - sexually active, non-contracepting and non-lactating) among women 15 to 49 year old". 4 Secondary infertility refers to the inability to conceive following a previous pregnancy. Globally, most infertile couples suffer from primary infertility. ${ }^{5}$

An infertility evaluation should be performed if a couple has not achieved conception after one year of unprotected intercourse. Evaluation is the starting point for treatment of infertility as it may suggest specific causes and appropriate treatment modalities. Although the history and physical examination provide important information, specific diagnostic tests are required to evaluate infertility. Because the causes of infertility can be multifactorial, a systematic approach typically is used and involves testing for male factor, ovulatory factor, uterotubal factor, and peritoneal factor. Many of these 
diagnostic tests are laboratory based, including semen analysis, serum progesterone level, and serum basal follicle - stimulating hormone level. ${ }^{6}$

The appropriate selection of investigations based on problem areas identified by history and physical examination would guide the physician in the management of the infertile couple. ${ }^{7}$

Laparoscopy has been suggested as a mandatory step to preclude the existence of peritubal adhesions and endometriosis as causes of infertility. ${ }^{8}$

Laparoscopy is now a days a gold standard for evaluating fallopian tube morphology and it can also be used for endometriosis diagnosis as if one centimetre lesion can only be diagnosed by laparoscopy and in cases of chronic pelvic pain and to rule out adnexal pathology and congenital defects. This study further focus the role of laparoscopy in finding out the causes of infertility in a rural set up. It also emphasizes the importance of laparoscopy as a basic skill which should be done in every case of infertility.

\section{METHODS}

It was a cross sectional study carried out in the department of obstetrics and gynaecology at Acharya Vinoba Bhave Rural Hospital Sawangi Wardha from August 2011 to July 2013, cases with infertility coming in the OPD were selected after taking informed consent. 100 cases of both primary and secondary infertility were considered. Cases excluded were infertility with male factor and patients with absolute contraindication for laparoscopy i.e. patients with cardiopulmonary disease, diaphragmatic hernia, large abdominal masses, paralytic ileus, gross obesity, generalized peritonitis, bowel obstruction, intraperitoneal haemorrhage, .

Firstly, complete history along with complete systemic examination of all the systems, along with per speculum and per vaginal examination were done. After taking informed consent laparoscopy was done under GA, during the post menstrual phase in $7^{\text {th }}, 8^{\text {th }}$ and $9^{\text {th }}$ day of cycle, pre-operative findings was noted. Chromopertubation with methylene blue dye was carried out to know the patency of the tubes. Tubal, ovarian, uterine and peritoneal factors were assessed and further management plan was made accordingly.

\section{RESULTS}

In our present study we found out that out of 100 cases of infertility, there were 75 cases $(75 \%)$ of primary infertility, and 25 cases (25\%) of secondary infertility (Table 1) We also found that maximum number of cases falls in the age group of 20-25 years that is 40cases $(40 \%)$ followed by 33 cases $(33 \%)$ in $26-30$ years and least number in the age group of more than 40 years that is 03 cases $(03 \%)$ (Table 2). Maximum number of primary infertility cases were in the age group of 20-25 years that is 34 cases $(45.33 \%)$ and that of secondary infertility maximum number of cases were in the 26-30 years age group that is 09 cases $(36 \%)$ (Table 3 ).

Table 1: Duration of infertility according to the type of infertility.

\begin{tabular}{|lll|}
\hline & Number of cases & $\%$ of cases \\
\hline Primary infertility & 75 & $75 \%$ \\
\hline $\begin{array}{l}\text { Secondary } \\
\text { infertility }\end{array}$ & 25 & $25 \%$ \\
\hline Total & 100 & $100 \%$ \\
\hline
\end{tabular}

Table 2: Age distribution in infertility cases.

\begin{tabular}{|lll|}
\hline Age in years & Number of cases & $\%$ of cases \\
\hline $20-25$ & 40 & $40 \%$ \\
\hline $26-30$ & 33 & $33 \%$ \\
\hline $31-35$ & 14 & $14 \%$ \\
\hline $36-40$ & 10 & $10 \%$ \\
\hline$>40$ & 03 & $3 \%$ \\
\hline Total & 100 & $100 \%$ \\
\hline
\end{tabular}

Table 3: Age distribution in primary and secondary infertility.

\begin{tabular}{|llll|}
\hline $\begin{array}{l}\text { Age in } \\
\text { years }\end{array}$ & $\begin{array}{l}\text { Primary } \\
\text { infertility } \\
(\mathbf{n = 7 5 )}\end{array}$ & $\begin{array}{l}\text { Secondary } \\
\text { infertility } \\
(\mathbf{n = 2 5})\end{array}$ & $\begin{array}{l}\text { Total } \\
(\mathbf{n = 1 0 0})\end{array}$ \\
\hline $20-25$ & $34(45.33 \%)$ & $06(24 \%)$ & $40(40 \%)$ \\
\hline $26-30$ & $24(32 \%)$ & $09(36 \%)$ & $33(33 \%)$ \\
\hline $31-35$ & $06(8 \%)$ & $08(32 \%)$ & $14(14 \%)$ \\
\hline $36-40$ & $04(5.33 \%)$ & $06(24 \%)$ & $10(10 \%)$ \\
\hline$>40$ & $01(1.33 \%)$ & $02(8 \%)$ & $03(3 \%)$ \\
\hline
\end{tabular}

Uterine causes contributed about 14 cases (14\%) among which 10 cases $(13.33 \%)$ were of primary infertility and 04 cases $(16 \%)$ were of secondary infertility. Tubal causes (peritubal adhesions, tubal blockage, tubo ovarian masses and hydrosalpinx) contributed about 34 (34\%) cases, among which 28 cases $(37.33 \%)$ were of primary infertility and 06 cases (24\%) were of secondary infertility. Ovarian factors (PCODS, bald ovaries streak ovaries, ovarian cysts) accounted for 27 cases (27\%) among which 19 cases $(25.33 \%)$ were of primary infertility and 08 cases $(32 \%)$ were of secondary infertility. Peritoneal causes (endometriosis, genital tuberculosis, adhesions) contributed for 07 cases $(7 \%)$ among which 05 cases $(6.66 \%)$ were of primary infertility and 02 cases $(8 \%)$ were of secondary infertility. Unexplained infertility accounted for 18 cases (18\%), among which primary infertility were 13 cases $(17.33 \%)$ and secondary infertility were 05 cases $(20 \%)$ (Table 4$)$. 
Table 4: Causes of infertility on laparoscopy.

\begin{tabular}{|llll|}
\hline Causes & $\begin{array}{l}\text { Primary } \\
\text { infertility } \\
(\mathbf{n = 7 5})\end{array}$ & $\begin{array}{l}\text { Secondary } \\
\text { infertility } \\
(\mathbf{n}=\mathbf{2 5})\end{array}$ & $\begin{array}{l}\text { Total } \\
(\mathbf{n}=\mathbf{1 0 0})\end{array}$ \\
\hline Uterine causes & $10(13.33 \%)$ & $04(16 \%)$ & $14(14 \%)$ \\
\hline Tubal causes & $28(37.33 \%)$ & $06(24 \%)$ & $34(34 \%)$ \\
\hline Ovarian causes & $19(25.33 \%)$ & $08(32 \%)$ & $27(27 \%)$ \\
\hline $\begin{array}{l}\text { Peritoneal } \\
\text { causes }\end{array}$ & $05(6.66 \%)$ & $02(8 \%)$ & $07(7 \%)$ \\
\hline Unexplained & $13(17.33 \%)$ & $05(20 \%)$ & $18(18 \%)$ \\
\hline
\end{tabular}

\section{DISCUSSION}

In this study 75 cases $(75 \%)$ were of primary infertility, and 25 cases $(25 \%)$ were of secondary infertility. The prevalence of primary and secondary infertility was similar to the study of Avasthi Kumkum et al. (2006) ${ }^{9}$ and Sharma N et al. (2012). ${ }^{10}$ There is overall higher incidence of primary infertility in the population (Table 1). ${ }^{11}$ This study also showed that maximum number of cases falls in the age group of 20-25 years that is 40 cases $(40 \%)$ followed by 33 cases $(33 \%)$ in the age group of 26-30 years and least number in the age group of more than 40 years that is 03 cases $(03 \%)$. Maximum number of primary infertility cases falls in the age group of 20-25 years that is 34 cases $(45.33 \%)$ and that of secondary infertility maximum number of cases falls in the 26-30 years age group that is 09 cases $(36 \%)$. Similarly according to Paul C. Adamson et al. $(2011)^{12}$ the prevalence of primary infertility in India was $12.6 \%$ and the mean age was 25.9year range was aged 15-30 year. Roupa Z et al. (2009) ${ }^{13}$ studied 110 infertile women, $64.5 \%$ were $20-29$ years, $20.0 \%$ were $30-39$ years, $11.8 \%$ were $40-49$ years and $3.7 \%$ were over 50 years.

In the present study, uterine causes was found in 14 cases (14\%), among which 10 cases $(13.33 \%)$ were of primary infertility and 04 cases (16\%) were of secondary infertility. Tubal causes (peritubal adhesions, tubal blockage, tubo ovarian masses and hydrosalpinx) contributed about 34 (34\%) cases, among which 28 cases $(37.33 \%)$ were of primary infertility and 06 cases (24\%) were of secondary infertility. Ovarian factors (PCODS, bald ovaries streak ovaries, ovarian cysts) accounted for 27 cases $(27 \%)$ among which 19 cases $(25.33 \%)$ were of primary infertility and 08 cases $(32 \%)$ were of secondary infertility. Peritoneal causes (endometriosis, genital tuberculosis, adhesions) contributed for 07 cases $(7 \%)$ among which 05 cases $(6.66 \%)$ were of primary infertility and 02 cases $(8 \%)$ were of secondary infertility. Unexplained infertility accounted for 18 cases (18\%); among which primary infertility were 13 cases $(17.33 \%)$ and secondary infertility were 05 cases $(20 \%)$.

Aziz N (2010) ${ }^{14}$ studied Fifty infertile women who underwent laparoscopy, $32(64 \%)$ had primary infertility while 18 (36\%) secondary infertility. Eight (25.0\%) patients with primary and $2(11.1 \%)$ patients with secondary infertility had no visible abnormality. The common finding was tubal blockage in $7(21.9 \%)$ and 6 $(33.3 \%)$ cases of primary and secondary infertility respectively. Five $(15.6 \%)$ cases of primary infertility were detected as polycystic ovaries (PCO) which was not found in cases of secondary infertility. Endometriosis was found in $4(12.5 \%)$ cases with primary infertility and 2 $(11.1 \%)$ cases with secondary infertility. Pelvic inflammatory disease (PID) was found in $1(3.1 \%)$ and 2 $(16.7 \%)$ cases of primary and secondary infertility respectively. Peritubal and periovarian adhesions were detected in $2(6.3 \%)$ cases with primary infertility and 4 $(22.2 \%)$ cases with secondary infertility. Fibroid was found in $2(6.3 \%)$ and $1(5.6 \%)$ cases of primary and secondary infertility respectively. Ovarian cyst detected in $2(6.3 \%)$ cases with primary infertility while none was found in cases of secondary infertility.

According to Riffat $\mathrm{S}$ et al. ${ }^{15}$ in 2010 , laparoscopy was done in 260 patients, ovulatory failure was found out to be $22.09 \%$, tubal blockage was found to be $14.41 \%$ \& tubal blockage with tuboovarian mass was found to be $1.31 \%$ and endometriosis was found out to be $6.55 \%$.Similar study was done by Cahill et al. ${ }^{16}$ who found $31 \%$ patient had PID, $5 \%$ had endometriosis. Tsuji I et al. ${ }^{17}$ in 2009 stated that 57 infertile patients with normal HSG findings underwent diagnostic laparoscopy. In $46(80.7 \%)$ of these patients, diagnostic laparoscopy revealed pathologic abnormalities. Specifically, endometriosis and peritubal and/or perifimbrial adhesions were found in $36(63.2 \%)$ and $5(8.8 \%)$ of the patients, respectively.

\section{CONCLUSIONS}

Infertility is a global health issue none of the female should be denied of her motherhood, it is a social stigma but efforts could be made for making a couple complete with a family. We are able to detect the cause(s) of infertility in the pelvic cavity and were able to design a suitable management plan, which could lead to postoperative pregnancy. Laparoscopy is gold standard for tubal and ovarian causes and in cases of endometriosis and in adhesions till date no other technology is present hence laparoscopy can used for evaluation of almost all the cases of infertility. Diagnostic laparoscopy has become so important in the evaluation of infertility that it has now been considered as a basic skill which should be learnt by every gynaecologist in the advanced scientific era. Because of the potential diagnostic and therapeutic benefits, patients with infertility should undergo laparoscopy prior to ART.

Funding: No funding sources Conflict of interest: None declared

Ethical approval: The study was approved by the institutional ethics committee 


\section{REFERENCES}

1. Poppe K, Velkeniers B. Thyroid and infertility. Verh K Acad Geneeskd Belg. 2002;64(6):389-99.

2. World Health Organization. Infecundity, infertility, and childlessness in developing countries. DHS Comparative Reports No 9. Calverton, Maryland, USA: ORC Macro and the World Health Organization; 2004. Available at: www.who.int/.

3. S Shamila and SL Sasikala. Primary Report on the Risk Factors Affecting Female Infertility in South Indian Districts of Tamil Nadu and Kerala. Indian J Community Med. 2011 Jan-Mar;36(1):59-61.

4. Reproductive health indicators for global monitoring: Report of the second interagency meeting, 2001. Geneva: World Health Organization; 2001: 23. Available at: www.who.int/reproductivehealth/publications/monit oring/en/.

5. Inhorn MC. Global infertility and the globalization of new reproductive technologies: illustrations from Egypt. Soc Sci Med. 2003;56:1837-51.

6. Makar RS, Toth TL. The evaluation of infertility. Am J Clin Pathol. 2002 Jun;117 Suppl:S95-103.

7. $\mathrm{Yu}$ SL, Yap C. Investigating the infertile couple. Ann Acad Med Singapore. 2003 Sep;32(5):611-3.

8. Fatum M, Laufer N, Simon A. Investigation of the infertile couple: should diagnostic laparoscopy be performed after normal hysterosalpingography in treating infertility suspected to be of unknown origin? Hum Reprod. 2002 Jan;17(1):1-3.

9. Avasthi Kumkum, Kaur Jasmine, Gupta Shweta, et al. Hyperprolactinema and its correlation with hypothyroidism in infertile women. J Obstet Gynecol India. 2006;56:68-71.

10. Sharma N, Baliarsingh S, Kaushik GG. Biochemical association of hyperprolactinemia with hypothyroidism in infertile women. Clin Lab. 2012;58(7-8):805-10.

11. Inhorn MC. Global infertility and the globalization of new reproductive technologies: illustrations from Egypt Soc Sci Med. 2003;56:1837-51.

12. Paul C Adamson. Prevalence and correlates of primary infertility among young women in Mysore, India. Indian J Med Res. 2011 October;134:440-6.

13. Roupa Z, et al. Causes of infertility in women at reproductive age. Health Science Journal. 2009;3(2):80-7.

14. Aziz N. Laparoscopic evaluation of female factors in infertility. J Coll Physicians Surg Pak. 2010 Oct;20(10):649-52.

15. Riffat $S$, et al. Prevalence of infertility in a cross section of Pakistani population Pakistan. J Zool. 2010;42(4):389.

16. Cahill DJ, Cooke IE, Darling MR. The influence of laparoscopy on infertility management. Ir J Med Sci. 1991 Feb;160(2):50-1.

17. Tsuji I, Ami K, Miyazaki A, Hujinami N, Hoshiai H. Benefit of diagnostic laparoscopy for patients with unexplained infertility and normal hysterosalpingography findings. Tohoku J Exp Med. 2009 Sep;219(1):39-42.

DOI: $10.5455 / 2320-1770 . i j r \operatorname{cog} 20140337$

Cite this article as: Samal S, Agrawal S, Agrawal M. Role of laparoscopy in infertility in a rural setup hospital. Int J Reprod Contracept Obstet Gynecol 2014;3:185-8. 